\title{
Hermenêutica Bíblica: prolongamentos de sentidos a partir da modernidade
}

\author{
Biblical Hermeneutics: extensions of meanings from \\ modernity
}

\section{Hermenéutica Bíblica: extensiones de significados desde la modernidad}

\author{
Profa. Dra. Suely \\ Xavier dos Santos* \\ Submetido em: 26-3-2021 \\ Aceito em: 10-5-2021
}

\author{
* Universidade Metodista de São Paulo. \\ Doutora em Ciências da Religião pelo PPG em Ciên- \\ cias da Religião UMESP; docente de Antigo Testamen- \\ to na Faculdade de Teologia e no PPG em Ciências da \\ Religião, UMESP; membro da Associação Brasileira de \\ Pesquisa Bíblica (ABIB) \\ suely.santos@metodista.br
}

\begin{abstract}
RESUMO
O estudo da Bíblia passa por diversas fases até chegar ao que se vê hoje numa relação de busca de sentidos e de releituras que coloquem a narrativa em planos diversificados de leitura, para isso é necessário revisitar os métodos de interpretação e, ao mesmo tempo, ampliar o diálogo com as ciências da modernidade, as quais colocamos em evidência, principalmente aquelas que superaram o positivismo metodológico. É necessário fazer o exercício constante de atualização, no sentido de colocar as discussões hermenêuticas em evidência no presente a partir das propostas já colocadas como forma de leitura e interpretação da Bíblia. E é sobre isto que este artigo pretende versar, a saber, apresentar os prolongamentos de sentidos na modernidade, a partir das diversas discussões atuais a respeito da leitura e interpretação da Bíblia.

Palavras-chave: hermenêutica; Bíblia; releituras; texto; modernidade.
\end{abstract}

\begin{abstract}
The study of the Bible goes through several phases until it reaches what is seen today in a relationship of search for meanings and reinterpretations that place the narrative in diverse reading plans, for this it is necessary to revisit the methods of interpretation and, at the same time, expand the dialogue with the sciences of modernity, which we highlight, mainly, those that have overcome methodological positivism. It is necessary to do the constant exercise of updating in order to put the hermeneutical discussions in evidence in the present from the proposals already put forward as a way to read and interpret the Bible. And this is what this article intends to deal with, namely, to present the extensions of meanings in modernity from the various current discussions regarding the reading and interpretation of the Bible. Key words: Hermeneutics; Bible; reinterpretations; text; modernity.

\section{RESUMEN}

El estudio de la Biblia pasa por varias fases hasta llegar a lo que se ve hoy en una relación de búsqueda de significados y reinterpretaciones que colocan la narrativa en diversos planes de lectura, para ello es necesario revisar los métodos de interpretación y, al mismo tiempo,
\end{abstract}


ampliar el diálogo con las ciencias de la modernidad, que hemos destacado, especialmente aquellas que han superado el positivismo metodológico. Es necesario hacer el ejercicio constante de actualización, para poner en evidencia en el presente las discusiones hermenéuticas a partir de las propuestas ya planteadas como forma de lectura e interpretación de la Biblia. Y de eso se trata este artículo, es decir, de presentar las extensiones de significados en la modernidad, a partir de las diversas discusiones actuales sobre la lectura e interpretación de la Biblia.

Palabras-clave: Hermenéutica; Biblia; reinterpretaciones; texto; modernidad.

\section{Hermenêutica em perspectiva: questões introdutórias}

Este artigo aborda algumas inquietações e um processo em construção a respeito da leitura e interpretação da Bíblia a partir da modernidade. Ao longo do tempo, a nossa percepção da complexidade que envolve o tema se ampliou tal qual as possibilidades da realização da tarefa de ler e interpretar a Bíblia na atualidade. Há uma profusão de perspectivas hermenêuticas atreladas a vários processos de construções ideológicas e identitárias que nos fazem refletir sobre como a Bíblia tem sido tratada na modernidade.

Há também que se pensar sobre quais as contribuições dos estudos hermenêuticos em um cenário de grandes mudanças, em todos os sentidos, que promova uma reflexão que leve em conta a tríade autor-texto-leitor como ponto de partida para a abordagem de qualquer natureza, mas com algumas reflexões pertinentes ao tema de forma a construir caminhos interpretativos relevantes e contributivos para uma leitura da narrativa bíblica. Não podemos adotar um olhar a-bistórico ou desprezar as ciências, ${ }^{1}$ como tem acontecido nos últimos tempos, quem sabe fruto da chamada "pós-modernidade" e suas complexas discussões, especialmente quando lemos as narrativas bíblicas e as interpretamos. Se faz necessário uma abordagem que leve em consideração os pequenos começos da interpretação bíblica e como esse processo se deu contribuindo para a abertura, até difusa, da leitura e interpretação da Bíblia na atualidade.

Cabe lembrar que o estudo da Bíblia a partir da modernidade ampliou as leituras e releituras com o uso das mais diversas ciências para aproximação do texto bíblico. Seja por meio do método histórico-crítico, em processo de revisão, seja por meio da arqueologia, seja por meio das Ciências da Linguagem e outras, há um ganho significativo quando se propõe a ampliar as possibilidades de leitura e interpretação do texto, com aproximações de seus limites e fronteiras e, ao mesmo tempo, ultrapassando as mesmas.

\footnotetext{
1 Boaventura de Souza Santos, em seu texto "Um discurso sobre as ciências", apresenta uma discussão interessante e complexa sobre as transformações que as ciências vêm sofrendo ao longo do tempo, bem como a diluição de fronteiras entre senso comum e conhecimento científico, não no sentido de valorar o que é mais importante, mas ampliar as possibilidades de ambas e suas contribuições no campo do saber/conhecer. Cf. SANTOS, Boaventura S. Um discurso sobre as ciências. São Paulo: Cortez, 2008.
} 
Pensar na perspectiva de leitura bíblica a partir da modernidade requer um olhar para o retrovisor, observar os que nos precederam nesta tarefa e prolongar os sentidos interpretativos. Há que se levar em conta a trajetória da composição e leitura da Bíblia, em suas tradições e transformações, ao longo do tempo. Se ela foi formada a partir do cotidiano das famílias, tribos e comunidades, muda essa perspectiva quando essa leitura passa pela institucionalização da igreja, cuja palavra final a respeito da intepretação é dada por esta. Na sequência, há um processo de desvinculação da Bíblia em relação ao seu solo primeiro, o cotidiano. A Reforma Protestante dá relevância objetiva à leitura da Bíblia, na medida em que propõe um retorno ao "sacerdócio universal de todos os crentes" e redimensiona o papel do/a leitor/a nesta tarefa. Claro que há fatores históricos que levaram a essa possibilidade, mas há que se reconhecer a necessidade de uma leitura primeira do texto. Aquela que vem da leitura devocional ou, quem sabe, a partir da "eixegese".

Com a modernidade, a leitura da Bíblia é levada para a "academia", agora com métodos próprios de interpretação, com formas e estruturas que não permitem uma leitura "despretensiosa". É necessário fazer a "exegese", o estudo formal do texto, para falar melhor sobre ele. Interessante que o movimento de tensão criado entre leitura acadêmica e leitura cotidiana pastoral tenha em Karl Barth (1886-1968) a proposta de uma reavaliação do sentido e significados da intepretação para a vida diária. Não há uma exclusão de métodos de intepretação, mas a necessidade do uso dos mesmos para lidar com os desafios na leitura da vida cotidiana com suas vicissitudes. Contudo, é na leitura popular da Bíblia, em solo latino-americano, que essa tensão amplifica e encontra seus limites e, por isso, se faz necessário centrar ainda mais o texto no chão da história de quem lê. Neste sentido, a Bíblia precisa fazer sentidos e promover sentidos de pertença ao leitor.

Sendo assim, o estudo da Bíblia passa por diversas fases até chegar ao que se vê hoje numa relação de busca de sentidos e de releituras que coloquem a narrativa em planos diversificados de leitura e interpretação, ou seja, é necessário revisitar os métodos e, ao mesmo tempo, ampliar o diálogo com as ciências da modernidade, as quais colocamos em evidência, principalmente aquelas que superaram o positivismo metodológico. Quem sabe não haja uma teleologia nessa proposta, mas é necessário fazer esse exercício constante de

\footnotetext{
2 Kaefer, em seu artigo "Hermenêutica bíblica: refazendo caminhos", apresenta a diferença entre eixegese, exegese e hermenêtica, que nos ajuda a pensar sobre a perspectiva de quem lê e interpreta a narrativa bíblica em horizonte de sentidos distintos. Conforme KAEFER, José Ademar. Hermenêutica bíblica: refazendo caminhos. Estudos de Religião, v. 28, n. 1, p. 115-134, jan.-jun. 2014. Disponível em: https://www.metodista.br/revistas/revistas-ims/index.php/ER/article/view/4777/4248. Acesso em 03 mai 2021.
} 
atualização, no sentido de colocar o texto em evidência no presente, a partir das propostas já colocadas como forma de leitura e interpretação da Bíblia.

Neste artigo, abordaremos a contribuição de Schleiermacher como ponto de partida para uma ruptura com a leitura e intepretação feita até o século XVIII, para, na sequência, refletir sobre as discussões que estão sempre em pauta e convergem para contribuições muito pertinentes ao tema, que é a questão do foco no leitor, no autor ou no texto, mas apontando suas contribuições e limites na interpretação da Bíblia na modernidade.

\section{A desregionalização da hermenêutica}

As perspectivas modernas de interpretação da Bíblia, de alguma forma, ainda carregam desafios que remontam ao início da modernidade. A partir da contribuição de Schleiermacher, ao propor uma desregionalização da hermenêutica, desde então centradas na filologia dos textos clássicos e na exegese de textos sagrados, há uma proposta de alargamento da intepretação e diluição das fronteiras eclesiásticas e mundo moderno. A hermenêutica passou a visitar vários espaços e áreas do saber. Claro que há de se considerar os equívocos na proposta de Schleiermacher, descritas por Ricouer, pois ele pensa sua teoria a partir de uma perspectiva "romântica" e "crítica" na abordagem da hermenêutica, o que se tornou um problema para a condensação de sua teoria, mas que foi ampliado a partir de seus seguidores. Tais problemas se dão porque a perspectiva romântica parte de uma compreensão de que é possível conhecer o autor em seu contexto até melhor do que ele mesmo se compreendeu; já a perspectiva crítica, por seu desejo "de criar regras universalmente válidas para compreensão" (RICOUER, 1990, p. 21). De fato, esses dois polos visitam as discussões sobre a hermenêutica bíblica ao longo da história da interpretação a partir do referido autor.

No que se refere ao aspecto "romântico", há uma perspectiva de que é possível conhecer o autor e seu contexto. Contudo, isso tem sido superado nas ciências bíblicas, que tem seu referencial no texto em si. Claro que há que se acercar da proposta de Dilthey, em que a realidade do texto é uma realidade histórica em si. Contudo, conhecer o autor, especialmente se pensarmos na tradição bíblica como memória popular, é um exercício fadado ao fracasso de saída. As novas propostas de leitura da Bíblia, que percebem a trama que existe em cada texto, impossibilitam essa aproximação com o autor.

No que se refere ao contexto, o uso da Crítica Literária, e até mesmo da Arqueologia, nos ajuda a perceber as tramas de cada perícope e, consequentemente, nos leva próximo ao contexto, seja por meio da tradição, da língua ou da reconstrução textual. Mas, de igual modo, passa por uma interpretação 
de quem faz uso dos métodos e, por isso, são contextos recriados e relidos a partir das ferramentas utilizadas para a abordagem do texto.

Nesta perspectiva, durante muito tempo os estudos bíblicos tiveram grande preocupação com a busca da autoria dos textos. A ideia é que conhecendo os produtores ou produtoras dos textos, ou suas comunidades, haveria uma proximidade maior entre o leitor e o autor na busca do contexto para uma maior compreensão do mesmo. Neste sentido, a dimensão romântica da proposta de Schleiermacher demarcou os estudos por um longo período. O método histórico-crítico teve papel especial na busca de interpretar o texto a partir de seu autor e seu contexto. Os novos estudos literários colocam em dúvida não só o papel do autor de uma obra, mas também se realmente há uma possibilidade de chegarmos a ele por meio do texto, ou até mesmo em seu contexto vital.

Quanto à questão "crítica", falar em regras de interpretação universalmente válidas é se mover em uma esfera que não percebe as questões próprias da subjetividade do intérprete, e aqui com a possibilidade de levar em consideração o seu contexto. A própria questão da universalidade da intepretação invalida a perspectiva de abertura da narrativa bíblica com suas possibilidades de serem relidas e reinterpretadas em outros contextos. O que de fato não se apresenta como provável em um mundo com saber globalizado e, ao mesmo tempo, local. Ou seja, há uma globalização que não deixa de lado o que é próprio, no sentido de constituição histórica, de cada cultura.

Os desdobramentos da contribuição de Schleiermacher, que inicia com desregionalização, contribui significativamente para a abertura do diálogo na interpretação, além de possibilitar o prolongamento da discussão sobre a interpretação a partir da modernidade. Pois essa perspectiva deixou o legado de abertura e ampliação dos esforços em compreender a tríade autor-texto-leitor na perspectiva de uma leitura Bíblica em relação a outros campos do saber e, ao mesmo tempo, até superando a tríade e propondo outros olhares para as narrativas.

\section{Tessituras, narrativas e tramas}

A intepretação bíblica passa por processos de tessituras que se constroem na cotidianidade das comunidades e de seus desdobramentos. Neste caso, há que se falar de uma construção coletiva com narrativas que encontram no cotidiano a expressão de suas vicissitudes e de seus desafios expressando, por meio da espiritualidade, uma gama de sentidos que se estabelecem numa relação de alteridade. 
É importante compreender o processo em que se constrói as narrativas bíblicas dentro do conjunto que passa pela tradição oral e suas respectivas estruturas. Esta tradição permeia as narrativas e convive com a tradição escrita por muito tempo. Em um momento crítico para a vida do povo judeu, por exemplo, que é a volta do exílio da Babilônia, observamos o processo interpretativo dentro dos conjuntos da oralidade e da escrita num processo de reconstrução, em todos os sentidos, e há também que se reconstruir as narrativas a partir das releituras daquele e para aquele tempo. Arens, destacando a importância das tradições e suas releituras dentro do conjunto de tradução-explicação-atualização, especialmente neste período, salienta o seguinte:

Lia-se o texto em hebraico, língua sagrada do templo. O povo, porém, não entendia o hebraico, por isso se fazia a tradução para o aramaico (targum: "tradução"). E, em seguida, dava-se a explicação (darash: "explicar", "consultar") e, por fim, fazia-se a atualização (midrash: “atualizar”). (2007, p. 68).

Ora, há um processo de reinterpretação das tradições antigas na tríade tradução-explicação-atualização. O povo que volta do exílio perdeu o contato direto com o hebraico e, portanto, carecia de uma tradução, mas isso não era suficiente para a compreensão dos ensinamentos e, portanto, havia necessidade de se explicar e atualizar a mensagem. Esse processo se estende tal qual um caminho de percepções e múltiplos sentidos para quem ouve. Neste sentido, quando pensamos neste processo de interpretação e releitura, há que se considerar a cotidianidade das tradições e suas possibilidades de interpretação, o que Josgrilberg (2011, p. 42) chama de "puxar um fio", segundo ele, "puxar um fio do texto é também puxar um fio da vida, como no avesso de um tapete: as tramas da vida formam a textura dos fios que criam imagens, revelam e representam o modo de Deus falar com seu povo". Claro que, agora, a partir de outros elementos e percepções cotidianas, mas uma percepção que relê nas tradições antigas a narrativa de vida das pessoas e atualizam-na para um novo contexto.

As tramas dessa textura são vistas também nas construções teológicas que se dão neste período, a saber, a necessidade de reconstrução da vida, da cidade, da religião e das instituições. Há necessidade de viver a vida a partir de outros olhares, a partir de outras lentes, quiçá a partir de grupos formadores de uma nova concepção sobre os atos salvíficos de Deus na história. Quem sabe seja possível inserir aqui o conceito da desregionalização, descrito por Schleiermacher. Claro que num processo diacrônico, mas com percepção de um novo viés em releituras e contextos distintos. Há um prolongamento de sentido das tradições antigas, agora na percepção de quem retorna do exílio. 
Há uma demanda muita clara e objetiva nos processos de retorno, mas não um retorno ao mesmo lugar, mas um retorno a outro lugar redimensionado pelo viver em outra cultura e tradição de outro povo, que receberá releituras de tradições antigas a partir de novos mundos que, segundo Josgrilberg (2011, p. 45), "a Bíblia testemunha também uma diversidade de mundos e culturas, mesmo que ela se apresente também na unidade de um cânon. Diferentes espaços, diferentes épocas, culturas, etc". E é nessa diversidade de mundos que se insere o conjunto de interpretações que são amalgamadas pelas tradições que se constroem ao longo do tempo e recebem novos contornos com outros olhares presentificados, o que não exclui, ao mesmo tempo, a diluição das fronteiras interpretativas. Antes as deixam abertas para novas releituras.

Neste sentido, no processo de fechamento do cânon da Torá se estabelecem novas diretrizes de interpretação, pois as narrativas se inserem agora numa conjuntura de pertença a outras esferas, a saber: a institucionalização das tradições narrativas do texto e da vida do povo. A canonização da Torá tenta colocá-la dentro do crivo de intepretação institucional, mas, mesmo assim, há sentidos diversos na leitura e interpretação dos textos. Este cânon é um recorte dentro de uma tradição maior e elaborada dentro das microtradições de um povo, ou seja, o que temos é um recorte a partir de determinados olhares e para determinados fins. A própria releitura da Torá no Novo Testamento se abre para novas releituras traditivas e serão, igualmente, prolongadas em seus sentidos dentro de outro contexto.

\section{A dimensão do continuum no processo interpretativo}

A perspectiva de intepretação que centra no leitor sua possibilidade de interpretação tem ganhado destaque com o uso de novas leituras da Bíblia, especialmente com o uso de outras ciências, como as Ciências da Linguagem, por exemplo, e isso tem ampliado as possibilidades de releitura do texto. Mas também há que se refletir sobre a questão contextual de quem produz e de quem lê o texto. Orlandi (2001, p. 17) nos chama à atenção para o fato de que "o estudo da linguagem não pode estar apartado da sociedade que a produz", no caso da Bíblia seja a linguagem de quem escreve, seja na linguagem de quem recebe o texto e o interpreta. Ambas realidades confluem em prolongamentos de sentidos, pois, para esta autora, "todo discurso nasce no outro (intertextualidade): todo discurso nasce em outro (sua matéria-prima) e aponta para outro (seu futuro discursivo). Por isso, na realidade, não se trata nunca de um discurso, mas de um continuum" (ORLANDI, 2001, p. 18). Segundo Orlandi, há um continuum no processo de construção e releitura dos textos produzidos 
pela linguagem. No conjunto da intertextualidade da narrativa bíblica há que se levar em consideração o processo de construções identitárias que se servem de outras construções, ou tradições, para organizar os sentidos de quem está no entorno das narrativas. A partir daí ocorre a matéria-prima de tradições construídas em outras e que, ao mesmo tempo, aponta para outra no momento que não fecha a porta da interpretação, mas a deixa aberta a novas releituras e interpretações que se constituem neste processo continuum.

E é justamente nesta proposta de intertextualidade e de continuum que precisamos refletir sobre os processos de interpretação e recepção das narrativas bíblicas. $\mathrm{Na}$ intertextualidade encontram-se pessoas, lugares, visões de mundo, relações interpessoais, construções sociais da realidade, enfim, neste lugar, a interpretação parte de uma realidade interpretada e que se conecta com a realidade presente. Nesse ato continum, a hermenêutica é a intepretação da realidade que se vive, que passa pela oralidade que precede o texto e, em seguida, para a escrita num processo dialético de sentidos múltiplos. Vale lembrar que o que temos para reler das tradições da Bíblia são textos, contudo, textos que passaram por processos de constituição, interpretação e releitura. Por isso, a ideia de continuum nos ajuda a verificar, e até mesmo identificar como estes textos foram reinterpretados ao longo da história e que influências receberam em suas releituras. Como, por exemplo, na tradição neotestamentária segundo a narrativa de Mateus 7.24-27, em que Jesus fala sobre a construção da casa na rocha e não na areia, e quais as consequências de quem age desta ou daquela forma. A perspectiva de Jesus ao orientar seus seguidores a "construir sua casa na rocha" é de quem guia a sua vida pela Torá, a analogia aqui está posta: casa igual a vida; rocha igual a Torá. As releituras da Igreja identificaram a rocha não com a Torá, mas com o Cristo. Assim, há um continuum neste processo de leituras e releituras das tradições, seja na perspectiva veterotestamentária, neotestamentária ou pela tradição da igreja.

Há que se levar em consideração que o que conhecemos da tradição bíblica, a grosso modo, nos vem pelas tradições do Antigo Oriente Médio, das tradições veterotestamentária, tradições neotestamentárias, tradição dos Pais da Igreja e de leituras modernas da Bíblia. Assim sendo, há um processo de interpretação da realidade e reinterpretação dessa realidade a partir da ótica de cada período, o que nos coloca a necessidade de observar o processo continuun no sentido de que cada um em seu tempo refaz os caminhos da interpretação da Bíblia, quem sabe aqui resida a percepção de Cantarela, inspirado em Ricouer, "na leitura dos livros da Bíblia, bem como na de qualquer outra obra literária, a construção de sentido se pretende numa fusão de horizontes entre o presente e o passado" (2013, p. 13). 
Há estudos hoje que colocam o foco na "estética da recepção - teoria que destaca o leitor como polo dinamizador do processo da leitura do texto" (CANTARELA, 2013, p. 419), e é neste que se assenta a necessidade de se pensar nos horizontes sentidos que se encontram a partir do texto. A intertextualidade, em que pese os estudos sobre literatura, sempre evocará horizontes passados e presentes, conforme Gadamer (1900-2002), nas leituras e interpretações. Neste sentido, há que se considerar o texto como aquele que tem lacunas a serem preenchidas, e quem faz isso é o leitor. Segundo Cantarela,

Hoje se tem claro que qualquer que seja o método exegético adotado, qualquer que seja a perspectiva sob a qual empreendemos a leitura do texto bíblico, eles corresponderão a um "lugar hermenêutico" no qual nos situamos, seja para tomar o texto como objeto de estudo acadêmico, seja para alimentar a reflexão de interesse eclesial. Em outras palavras, o contexto geográfico de onde vem a pessoa, a classe social a que pertence, a bagagem cultural de que dispõe, o maior ou menor domínio de ferramentas exegéticas, o fato de ser homem ou mulher, a pertença a determinado tipo de Igreja, tudo isso condiciona, ainda que de forma não determinante, os resultados de sua leitura da Bíblia (ou de qualquer outro texto). (2013, p. 420-421).

Percebemos, então, a importância de se compreender "lugar hermenêutico" para identificarmos os sentidos atribuídos ao texto por quem lê. Há um conjunto de fatos que presentifica o passado em diversos atores e cenários, e que definirão como o texto está sendo lido. Como preenchedor de lacunas, o leitor se insere no conjunto interpretativo e alarga suas possibilidades de releitura.

\section{Considerações Finais}

A proposta deste artigo é colaborar com as discussões sobre Hermenêutica Bíblica na atualidade, especialmente em um período difuso na leitura e interpretação do texto sagrado, além de ilimitadas fronteiras de interpretação que se têm colocado nesta área. Há que se pensar na constituição de sentido na perspectiva de quem lê o texto Bíblico na produção de um continuum discursivo que leve em consideração a proposta do texto, mas também o lugar de sentido do leitor. Neste prolongamento de sentidos é que o texto vai se firmando, não pelas categorias científicas por si só, mas também pelas categorias distintas e produtoras de realidades que requerem uma postura diante da vida como um todo. Na modernidade, as construções de novas propostas de leitura e intepretação da Bíblia não invalidam ou inviabilizam outras, mas o que ocorre é a ampliação dos sentidos a partir das propostas existentes para a construção de outras. 
Pensar sobre interpretação da Bíblia, no contexto atual, em que observamos a intolerância e o esvaziamento do sentido da vida, requer proposições hermenêuticas que tragam para o centro dessa reflexão leituras e releituras que visem à preservação da vida em todos os sentidos, a saber, os focos de interpretação se diluem diante da necessidade de releituras que promovam relações de alteridade em nosso tempo. Numa sociedade em que a história e a ciência são colocadas em xeque, especialmente em função de leituras fundamentalistas e literais da Bíblia, revisitar o passado e percorrer as discussões sobre o tema da Hermenêutica Bíblica é um compromisso de quem deseja construir realidades objetivas e contributivas para abordagens que promovam discussões profícuas e relevantes para o tempo que se chama hoje!

\section{Referências bibliográficas}

ARENS, Eduardo. A bíblia sem mitos: uma introdução crítica. Trad. Celso Marcio Teixeira. São Paulo: Paulus, 2007.

CANTARELA, Antonio Geraldo. Questões de hermenêutica bíblica à luz da estética da recepção. Perspectiva Teológica, Belo Horizonte, v. 45, n. 127, p. 419-438, Set./Dez. 2013.

JOSGRILBERG, Rui S. Hermenêutica Bíblica e a vida cotidiana. Caminhando. v. 16, n. 1, p. 41-50, jan./jun. 2011; Disponível em:

https://www.researchgate.net/publication/276760018_Hermeneutica_Biblica_e_a_Vida_ Cotidiana/fulltext/55d7bae708aec156b9aa1e95/Hermeneutica-Biblica-e-a-Vida-Cotidiana. pdf.

ORLANDI, Eni P. Discurso e leitura. São Paulo; Campinas: Cortez; Editora da Unicamp, 2001.

RICOUER, Paul. Interpretação das ideologias. Rio de Janeiro: Francisco Alves, 1990. 